\title{
Why medical students choose psychiatry - a 20 country cross-sectional survey
}

Kitty Farooq ${ }^{1}$, Gregory J Lydall ${ }^{2}$, Amit Malik ${ }^{3}$ David M Ndetei ${ }^{4}$, ISOSCCIP Group and Dinesh Bhugra ${ }^{5^{*}}$

\begin{abstract}
Background: Recruitment to psychiatry is insufficient to meet projected mental health service needs world-wide. We report on the career plans of final year medical students from 20 countries, investigating factors identified from the literature which influence psychiatric career choice.

Methods: Cross sectional electronic or paper survey. Subjects were final year medical students at 46 medical schools in participating countries. We assessed students' career intentions, motivations, medical school teaching and exposure to psychiatry. We assessed students' attitudes and personality factors. The main outcome measure was likelihood of specializing in psychiatry. Multilevel logistic regression was used to examine the joint effect of factors upon the main outcome.
\end{abstract}

Results: 2198 of 9135 (24\%) of students responded (range 4 to 91\%) across the countries. Internationally 4.5\% of students definitely considered psychiatry as a career (range 1 to 12\%). 19\% of students (range 0 to 33\%) were "quite likely", and 25\% were "definitely not" considering psychiatry. Female gender, experience of mental/physical illness, media portrayal of doctors, and positive attitudes to psychiatry, but not personality factors, were associated with choosing psychiatry. Quality of psychiatric placement (correlation coefficient $=0.22, p<0.001$ ) and number of placements (correlation coefficient $=0.21, p<0.001$ ) were associated with higher ATP scores. During medical school, experience of psychiatric enrichment activities (special studies modules and university psychiatry clubs), experience of acutely unwell patients and perceived clinical responsibility were all associated with choice of psychiatry. Multilevel logistic regression revealed six factors associated with students choosing psychiatry: importance of own vocation, odds ratio (OR) 3.01, 95\% Cl 1.61 to 5.91, p<0.001); interest in psychiatry before medical school, OR 10.8 (5.38 to $21.8, p<0.001)$; undertaking a psychiatry special study module, OR $1.45(1.05$ to $2.01, p=0.03$ ) or elective OR 4.28 (2.87- 6.38, p < 0.001); membership of a university psychiatry club, OR 3.25 (2.87 to 6.38, p<0.001); and exposure to didactic teaching, OR 0.54 ( 0.40 to $0.72, \mathrm{p}<0.001)$.

Conclusions: We report factors relevant to medical student selection and psychiatry teaching which affect career choice. Addressing these factors may improve recruitment to psychiatry internationally.

Keywords: Psychiatry, Career choice, Medical student, Attitude to psychiatry, Stigma, Enrichment activity, Recruitment, Gender, Medical school selection

\footnotetext{
* Correspondence: dinesh.bhugra@kcl.ac.uk

${ }^{5}$ Mental Health and Cultural Diversity, PO25, Health Service and Population Research Department, Institute of Psychiatry, King's College London, David Goldberg Centre, De Crespigny Park, London SE5 8AF, UK

Full list of author information is available at the end of the article
} 


\section{Background}

Psychiatry is facing a shortage of specialists, sometimes termed a "recruitment crisis" [1-4]. There is also a marked "Mental Health Gap" between the burden of mental health, substance misuse and neurological disorders worldwide, and resources [5]. The World Psychiatric Association (WPA) included recruitment to psychiatry as a major part of its 2008-2011 Action Plan [6]. There is a wide variation in psychiatric training opportunities worldwide [7-9] which is reflected in numbers of places available. For example with over 24,000 medical graduates each year in the UK, there are fewer than 450 new places for training in psychiatry, thus even if adequate numbers of people are interested, they may not be able to find jobs [10].

Reasons for low recruitment levels are varied. Studies of psychiatry career choice have generally been conducted at national levels [11-24], but not yet at a multinational level. The vast majority of literature identified in our systematic review was from the United States (36\%) and UK (25\%) [25]. These studies have examined personal and experiential factors as reasons why medical students may or may not choose psychiatry as their first career option.

Potential psychiatrists may decide on a career in psychiatry before, during, or after medical school. Factors associated with choosing psychiatric careers include exposure to psychiatrists or mental illness prior to medical school, and subsequent exposure to positive clinical experiences and "enrichment activities" such as electives and research to confirm their interest during medical school [26-28]. The summary of factors already identified as influencing career choice is shown in Table 1 and the effect of enrichment activities in our sample is shown in Table 2. Our literature search to identify these factors took included papers from 1999 onwards to try to reduce the impact of variation over time.

Generally around 3\% of students overall select psychiatry as a career [29], and those with positive attitudes towards mental health were around three times more likely to do so [18]. It is useful to understand what factors play a role especially across nations as doctors are global citizens and likely to move around more frequently.

In this study we focused on medical students because this group reflects medical school selection processes and the effects of psychiatry teaching and clinical exposure. This group may also be influenced by factors which medical educators and policy makers can address with sufficient evidence and will.

\section{Objectives}

To report on career plans of final year medical students in 46 medical schools from 20 countries, with reference to factors identified from the literature as influencing

Table 1 Published associations with choice of psychiatry as a career

\begin{tabular}{|c|c|}
\hline Factor & Effect \\
\hline Gender & More women students than men choose psychiatry \\
\hline Influences on choosing medicine & Personal or family experience of mental illness is more common \\
\hline Pre-medical school qualifications & $\begin{array}{l}\text { Students are no more likely to have previous degree, but, if they do, are more likely to have an arts or } \\
\text { humanities background }\end{array}$ \\
\hline School leaving qualifications & Students are more likely to have studied arts or humanities at school \\
\hline Pre-medical school career choice & Interest in psychiatry prior to medical school is maintained in the final year \\
\hline Quality of teaching & Positive correlation between teaching placement quality and ATP score \\
\hline Teaching exposure & $\begin{array}{l}\text { Positive correlation between the number of teaching exposures and ATP-18, and likelihood of choosing } \\
\text { psychiatry }\end{array}$ \\
\hline Enrichment activities & $\begin{array}{l}\text { Exposure to enrichment activities (special study modules, electives and university psychiatry clubs) increases } \\
\text { the likelihood of students choosing psychiatry }\end{array}$ \\
\hline Stage of exposure & Early or late clinical exposure during medical school makes no difference \\
\hline Duration of exposure & Positive correlation between placement length and likelihood of choosing psychiatry \\
\hline Setting of exposure & Experience of outpatient or specialist services increases choice of psychiatry than inpatient services \\
\hline Types of patients seen & Experience of people in recovery or people seeking help are more likely to choose psychiatry \\
\hline Responsibility during placement & $\begin{array}{l}\text { Positive correlation between higher levels of responsibility for patient care and likelihood of choosing } \\
\text { psychiatry }\end{array}$ \\
\hline $\begin{array}{l}\text { Perception of psychiatry compared to } \\
\text { other fields }\end{array}$ & Psychiatry is seen as having better job prospects, more flexibility, higher burnout and lower prestige \\
\hline ATP-18* & ATP-18 scores are positively correlated with choosing psychiatry \\
\hline Personality traits & $\begin{array}{l}\text { Those choosing psychiatry will score higher on measures of neuroticism and openness compared to those } \\
\text { choosing other fields }\end{array}$ \\
\hline
\end{tabular}

*ATP: Attitude to Psychiatry Scale. 
Table 2 Enrichment activities and relation to likelihood of choosing psychiatry

\begin{tabular}{|c|c|c|c|c|}
\hline Factor & Category & $\begin{array}{l}\text { Unlikely } \\
\text { N (\%) }\end{array}$ & $\begin{array}{l}\text { Likely } \\
\text { N (\%) }\end{array}$ & P-value \\
\hline \multirow{2}{*}{$\begin{array}{l}\text { Psychiatry special } \\
\text { study module }\end{array}$} & No & $1387(82 \%)$ & $311(18 \%)$ & \multirow[t]{2}{*}{0.03} \\
\hline & Yes & 297 (77\%) & 89 (23\%) & \\
\hline \multirow{2}{*}{$\begin{array}{l}\text { Research experience } \\
\text { in psychiatry }\end{array}$} & No & $1632(82 \%)$ & $368(18 \%)$ & \multirow[t]{2}{*}{$<0.001$} \\
\hline & Yes & $52(62 \%)$ & $32(38 \%)$ & \\
\hline \multirow{2}{*}{$\begin{array}{l}\text { University psychiatry } \\
\text { club }\end{array}$} & No & $1630(82 \%)$ & $351(18 \%)$ & \multirow[t]{2}{*}{$<0.001$} \\
\hline & Yes & $54(52 \%)$ & 49 (48\%) & \\
\hline \multirow{2}{*}{$\begin{array}{l}\text { National psychiatry } \\
\text { club }\end{array}$} & No & 1667 (81\%) & $391(19 \%)$ & \multirow[t]{2}{*}{0.05} \\
\hline & Yes & 17 (65\%) & $9(35 \%)$ & \\
\hline \multirow[t]{2}{*}{ Psychiatry elective } & No & 1561 (84\%) & $304(16 \%)$ & \multirow[t]{2}{*}{$<0.001$} \\
\hline & Yes & $123(56 \%)$ & $96(44 \%)$ & \\
\hline \multirow{2}{*}{$\begin{array}{l}\text { Problem-based } \\
\text { learning scenarios }\end{array}$} & No & 1253 (81\%) & $298(19 \%)$ & \multirow[t]{2}{*}{0.97} \\
\hline & Yes & $431(81 \%)$ & $102(19 \%)$ & \\
\hline \multirow[t]{2}{*}{ e-learning } & No & $1556(81 \%)$ & 368 (19\%) & \multirow[t]{2}{*}{0.79} \\
\hline & Yes & $128(80 \%)$ & $32(20 \%)$ & \\
\hline \multirow{2}{*}{$\begin{array}{l}\text { Psychiatry simulation } \\
\text { teaching }\end{array}$} & No & 1494 (82\%) & $342(19 \%)$ & \multirow[t]{2}{*}{0.07} \\
\hline & Yes & $190(77 \%)$ & $58(23 \%)$ & \\
\hline \multirow{2}{*}{$\begin{array}{l}\text { Visits to secure } \\
\text { units/prisons }\end{array}$} & No & $1204(81 \%)$ & $286(19 \%)$ & \multirow[t]{2}{*}{0.99} \\
\hline & Yes & $480(81 \%)$ & $114(19 \%)$ & \\
\hline \multirow[t]{2}{*}{ Lectures/tutorials } & No & $584(78 \%)$ & $166(22 \%)$ & \multirow[t]{2}{*}{0.01} \\
\hline & Yes & 1100 (82\%) & $234(18 \%)$ & \\
\hline \multirow[t]{2}{*}{ Specialist placement } & No & $1203(81 \%)$ & 279 (19\%) & \multirow[t]{2}{*}{0.50} \\
\hline & Yes & 481 (80\%) & $121(20 \%)$ & \\
\hline \multirow{2}{*}{$\begin{array}{l}\text { Optional extras } \\
\text { on course }\end{array}$} & No & 1590 (82\%) & $357(18 \%)$ & \multirow[t]{2}{*}{$<0.001$} \\
\hline & Yes & 94 (69\%) & 43 (31\%) & \\
\hline
\end{tabular}

psychiatry as a career choice. The null hypothesis was that these established factors predicting choice of psychiatry will have no association with respondents' career choices.

\section{Methods}

\section{Design and sample}

This study used a quantitative cross-sectional design. Using an existing network of early career psychiatrists, high, low and middle-income countries were identified to obtain a sample of countries with a wide variation in mental health care systems and health care spending. An opportunistic sample of medical schools was selected in each country. The whole population of final year students within each school was invited to participate in the study.

\section{Measurements}

We developed an online questionnaire which included questions on demographics, influences in choosing medicine, pre-medical school qualifications, pre-medical school career choice, and quality of teaching, clinical exposure, enrichment activities, and reported clinical placement responsibility during medical school. We included the ATP18 (Attitude to Psychiatry Scale [29], and International English Big 5 Mini-Markers scale [30] which have been validated in a number of populations.

The questionnaire was piloted in the UK in November 2009, using a sample drawn from student members of the Royal College of Psychiatrists, and is available on request. The study was performed in different countries between March 2010 and June 2011 taking into account large variations in the timescales of ethics applications, and different timings between Northern \& Southern Hemisphere term-times.

Where the local language was considered by local investigators to be preferable to English, the instruments were translated, back-translated, checked for accuracy and agreed translations were used. The final questionnaire was either sent out directly by a secure online survey service, or through email via a participating member of the medical school faculty. The exceptions were Japan and the African Mental Health Forum countries (excluding South Africa), which chose to use paper versions of the survey due to lack of Japanese language support from online tools, and limited internet access respectively.

Reminders were sent out at 4 and 8 weeks, and a standard protocol for maximising the response rate was followed including a short presentation to students before the reminders were sent out, and the use of local publicity and student representatives to raise the study profile and to prompt responses.

Ethical approval, where required, was obtained in each country's relevant institution. In the UK this was granted by each participating medical school's ethics panel.

\section{Power calculation}

Previous research [29] had suggested that around 3\% of students select psychiatry as a career; and that those medical students with positive attitudes towards psychiatry were around three times more likely to choose psychiatry as a career. To achieve a threefold difference it was assumed that $1.5 \%$ of those with negative attitudes, and $4.5 \%$ of those with positive attitudes would choose psychiatry as a career. To detect this level of difference with a 5\% significance level and 90\% power would require 1486 responses. It was originally envisaged that 3000 questionnaires would be distributed globally assuming a $50 \%$ response rate. However the response rate was low (17\%), so a greater number (9373) was distributed to increase the power.

\section{Statistical methods}

Categorical variables were summarised by the number and percentage of subjects in each category. Continuous 
variables were summarised using the mean and standard deviation.

Statistical analyses were performed using the program Stata v10. Significance level was set at 5\% ( $<<0.05$, 2-sided).

The primary analysis examined factors associated with the students reporting a choice of career in psychiatry. This variable was originally measured on a 5-point Likert scale (no way, unlikely, possible, seriously consider and definitely) and was taken from the instrument designed by Feifel [31]. For the purposes of analysis, this scale was reduced to a binary outcome, with students either being "unlikely" to specialise in psychiatry (no way, unlikely, possible), or "likely" to specialise in psychiatry (seriously consider, definitely). It was not considered appropriate to treat this outcome as a continuous variable for two main reasons. Firstly this would assume equal spacing of the categories, which is not necessarily the case with a subjective ordinal variable. Secondly if it was assumed that this variable is continuous, then the analysis methods would assume a normal distribution for this measure. This is not the case here as the values are skewed towards the lower end of the scale (i.e. not choosing psychiatry).

The association between categorical variables and this measure was assessed using the Chi-square test. Differences in continuous variables between the two groups were examined using the unpaired $t$-test.

An additional analysis examined the association between ATP-18 score and likelihood of choosing psychiatry, and perception of psychiatry relative to other fields. All variables were measured on either ordinal or continuous scales, using Spearman's rank correlation.

Personality traits were examined using the International English Mini-Markers scale, with permission from the author [30]. Each item was scored as being either inaccurate,' neutral' or 'accurate'. A score of 1-3 was attributed to each of these three categories. The scoring of personality traits that were negatively phrased was done using reverse coding. The total score for each trait was calculated, giving a value between 8 and 24. A higher value implied that the students associated themselves with that trait.

Differences in personality trait scores between students seriously considering specialising in psychiatry and those not seriously considering were assessed using the unpaired t-test.

We considered carefully whether to correct for multiple testing. We concluded that it was not necessary to employ this method in this situation where we were examining the effects of separate variables.

\section{Multilevel logistic regression}

It was predicted that responses from students in the same countries would be more similar than responses from students in different countries. To allow for this data structure, and the binary nature of the outcome variable (choice of psychiatry or not), the analysis was performed using multilevel logistic regression methods.

The original analysis examined the effect of a large number of variables upon the main outcome. To avoid overloading the regression model, this analysis was restricted to variables shown to have a probable level of association with the outcome from the initial analyses (variables with a p-value of $<0.2$, Tables 2 and 3 ), and a backwards selection procedure was employed. The latter involved removing the non-significant terms one at a time until only the statistically significant variables remained. Initially the ATP- 18 score was omitted from the analysis, because data on this score was only available for around half of participants. The inclusion of this variable would have restricted the number of students included in the

Table 3 Medical school clinical exposure factors and relation to likelihood of choosing psychiatry

\begin{tabular}{|c|c|c|c|c|}
\hline Factor & Category & $\begin{array}{l}\text { Unlikely } \\
\mathrm{N}(\%)\end{array}$ & $\begin{array}{l}\text { Likely } \\
\mathrm{N}(\%)\end{array}$ & P-value \\
\hline \multirow{3}{*}{$\begin{array}{l}\text { Time of psychiatry } \\
\text { placement }\end{array}$} & First half & $93(85 \%)$ & 17 (15\%) & 0.45 \\
\hline & 3rd quarter & $543(82 \%)$ & $123(18 \%)$ & \\
\hline & Final quarter & 715 (80\%) & 179 (20\%) & \\
\hline \multirow{3}{*}{$\begin{array}{l}\text { Weeks of } \\
\text { psychiatry } \\
\text { teaching }\end{array}$} & $\leq 5$ weeks & $648(82 \%)$ & 145 (18\%) & 0.43 \\
\hline & 6-10 weeks & $298(79 \%)$ & 81 (21\%) & \\
\hline & $11+$ weeks & $278(80 \%)$ & 70 (20\%) & \\
\hline \multirow{3}{*}{$\begin{array}{l}\text { Main psychiatry } \\
\text { placement } \\
\text { setting }\end{array}$} & Inpatient & $984(82 \%)$ & $216(18 \%)$ & 0.13 \\
\hline & Outpatient & $202(77 \%)$ & $61(23 \%)$ & \\
\hline & Specialist & 155 (79\%) & $40(21 \%)$ & \\
\hline \multirow{2}{*}{$\begin{array}{l}\text { Seen people } \\
\text { in crisis }\end{array}$} & No & $652(82 \%)$ & 146 (18\%) & 0.06 \\
\hline & Yes & $620(78 \%)$ & 175 (22\%) & \\
\hline \multirow{2}{*}{$\begin{array}{l}\text { Seen people } \\
\text { in recovery }\end{array}$} & No & $376(78 \%)$ & 105 (22\%) & 0.27 \\
\hline & Yes & 896 (81\%) & 216 (19\%) & \\
\hline \multirow{2}{*}{$\begin{array}{l}\text { Seen prodromal } \\
\text { symptoms }\end{array}$} & No & 913 (80\%) & 224 (20\%) & 0.48 \\
\hline & Yes & 359 (79\%) & 97 (21\%) & \\
\hline \multirow{2}{*}{$\begin{array}{l}\text { Seen patients } \\
\text { motivated to } \\
\text { seek help }\end{array}$} & No & $532(80 \%)$ & $130(20 \%)$ & 0.67 \\
\hline & Yes & 740 (79\%) & 191 (21\%) & \\
\hline \multirow{2}{*}{$\begin{array}{l}\text { Seen acutely } \\
\text { unwell patients }\end{array}$} & No & $522(82 \%)$ & $111(18 \%)$ & 0.04 \\
\hline & Yes & 750 (78\%) & $210(22 \%)$ & \\
\hline \multirow{2}{*}{$\begin{array}{l}\text { Seen people } \\
\text { with chronic } \\
\text { symptoms }\end{array}$} & No & 159 (880\%) & 39 (20\%) & 0.87 \\
\hline & Yes & 1113 (80\%) & $282(20 \%)$ & \\
\hline \multirow{4}{*}{$\begin{array}{l}\text { Level of } \\
\text { responsibility } \\
\text { during placement }\end{array}$} & None & 507 (79\%) & 135 (21\%) & $<0.001$ \\
\hline & Asked opinion & 417 (83\%) & 83 (17\%) & \\
\hline & First clerking & 215 (83\%) & 45 (17\%) & \\
\hline & $\begin{array}{l}\text { Assess risk/do } \\
\text { therapy }\end{array}$ & 135 (69\%) & 60 (31\%) & \\
\hline
\end{tabular}


analysis. However, subsequently the effect of this variable was also examined in the regression because attitudes to psychiatry are linked to career choice [18].

\section{Results}

A total of 2198 students from 46 medical schools in 20 countries consented to take part in the survey. The number of responses per country ranged from 9 (Tanzania) to over 300 (Germany). The spread of countries is represented in Figure 1, using 2011 World Bank (http://data.worldbank.org/indicator/) and World Health Organization (WHO) Global Health Expenditure (http:// apps.who.int/nha/database/DataExplorerRegime.aspx) data to illustrate gross domestic product (GDP) per capita and percentage of GDP spent on healthcare. A summary of the number of responses from each country, and demographic details are shown in Table 4.

Respondents had a mean age of 24 years. The majority (93\%) were home rather than international students, although this overall figure hid a wide variation between individual countries. $14 \%$ of students were from an ethnic minority within their country of study (range $0 \%$ to $55 \%$ ). $41 \%$ of the students were men, although this also varied by country (range $21 \%$ to $79 \%$ ). South American, Asian and African countries had a higher percentage of men respondents, whist the European countries and Canada had a higher proportion of women responding to the survey.

\section{Likelihood of specialising in psychiatry}

The primary analysis examined the likelihood of participants specialising in psychiatry. A summary of the proportion of respondents and their reported likelihoods of specialising in psychiatry by country along with demographic findings is shown in Table 4. The overall results suggested that $4.5 \%$ of respondents were "definitely" considering specialising in psychiatry, and another $15 \%$ were "seriously considering" specialising in the field, giving a combined "likely" total of $19 \%$. The variation in percentage of medical students seriously considering or definitely considering a career in psychiatry (combining 'definitely' and 'seriously considering' scores) is shown in Figure 2.

Interestingly there was a higher likelihood of choosing psychiatry in the European countries, with a lower likelihood in African countries. No students in Tanzania (although based on small numbers) and only 1\% in Uganda were likely to choose psychiatry. By comparison, up to $31 \%$ of students sampled in Chile and 33\% in Iraq were likely future psychiatrists.

\section{Pre-medical school factors associated with choosing psychiatry}

The first set of analyses examined the association between demographic details of the participants and choosing psychiatry. Women were more likely to choose psychiatry than men $(21 \%$ vs. $16 \%, p=0.007)$. There were no differences by ethnicity, social class or urbanicity. Not surprisingly personal or family experience of physical illness $(\mathrm{p}=$ $0.001)$ and mental illness $(\mathrm{p}<0.001)$ were likely to influence choice of speciality. Four factors that influenced the choice to study medicine were also found to be significantly associated with specialising in psychiatry: students' own vocation $(\mathrm{p}=0.02)$, the media portrayal of doctors/ medicine $(\mathrm{p}=0.03)$, and past experience of physical $(\mathrm{p}=$ $0.001)$ and mental illness $(\mathrm{p}<0.001)$.

No association was found between the students' qualifications before medical school and subjects studied at school, and their likelihood of specialising in psychiatry.

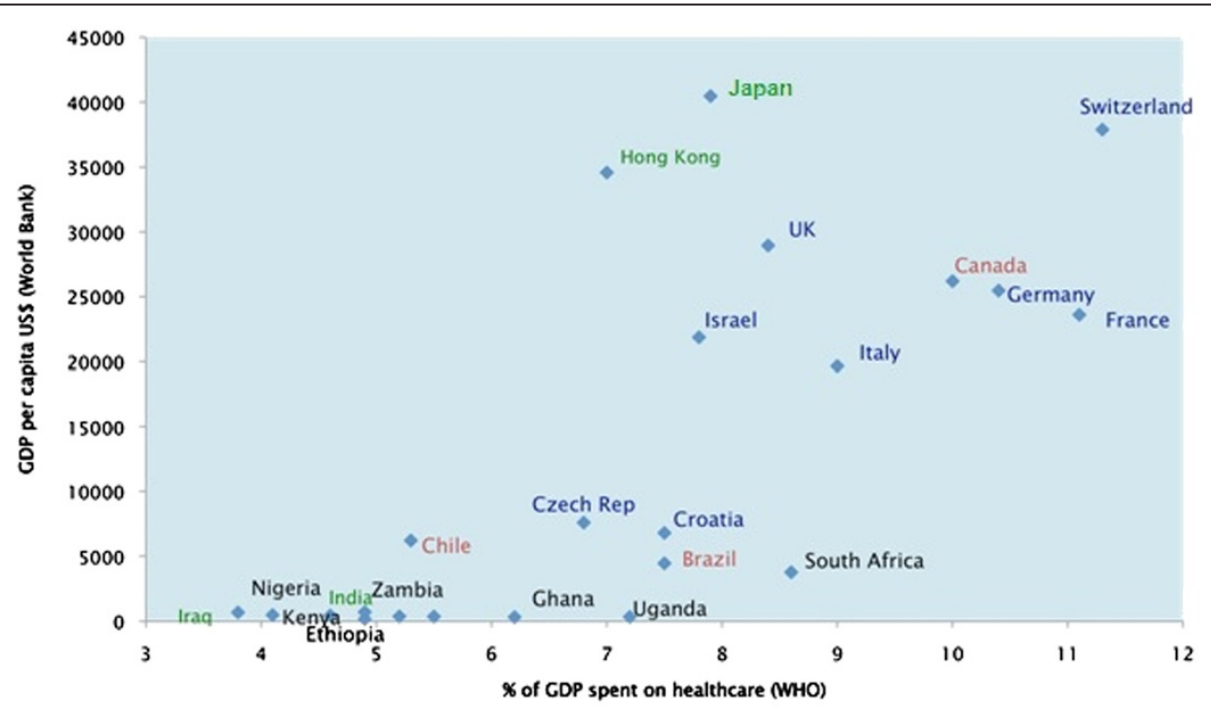

Figure 1 Participating countries' 2011 Gross Domestic Product (GDP) per capita vs. percentage healthcare spend. 
Table 4 Country response rates, demographics, and likelihood of choosing psychiatry

\begin{tabular}{|c|c|c|c|c|c|c|c|c|c|c|c|}
\hline Country & $\begin{array}{l}\text { Number of } \\
\text { responses }\end{array}$ & $\begin{array}{l}\text { Sample } \\
\text { size }\end{array}$ & $\begin{array}{l}\text { Response } \\
\text { rate \% }\end{array}$ & $\begin{array}{l}\text { Age, mean } \\
\text { (SD) }\end{array}$ & $\begin{array}{l}\text { International } \\
\text { student N (\%) }\end{array}$ & $\begin{array}{l}\text { Ethnic } \\
\text { minority } \\
\mathrm{N}(\%)\end{array}$ & $\begin{array}{l}\text { Male gender } \\
\mathrm{N}(\%)\end{array}$ & $\begin{array}{l}\text { No way would } \\
\text { choose psychiatry } \\
\text { N (\%) }\end{array}$ & $\begin{array}{l}\text { Seriously } \\
\text { considering } \\
\text { psychiatry } \mathrm{N}(\%)\end{array}$ & $\begin{array}{l}\text { Definitely } \\
\text { considering } \\
\text { psychiatry } \mathrm{N}(\%)\end{array}$ & $\begin{array}{l}\text { Likely to } \\
\text { choose psychiatry } \\
\mathrm{N}(\%) \neq\end{array}$ \\
\hline Croatia & 136 & 385 & $35 \%$ & $24.6(1.7)$ & $\mathrm{O}(0 \%)$ & $5(4 \%)$ & $37(28 \%)$ & $37(28 \%)$ & $21(16 \%)$ & $8(6 \%)$ & $29(22 \%)$ \\
\hline $\begin{array}{l}\text { Czech } \\
\text { Republic }\end{array}$ & 78 & 239 & $33 \%$ & $25.2(1.0)$ & $14(21 \%)$ & $6(9 \%)$ & $22(32 \%)$ & $22(31 \%)$ & $6(8 \%)$ & $5(7 \%)$ & $11(15 \%)$ \\
\hline France & 114 & 446 & $26 \%$ & $24.8(1.1)$ & $0(0 \%)$ & $(*)$ & 35 (32\%) & $45(40 \%)$ & 15 (13\%) & $13(12 \%)$ & $28(25 \%)$ \\
\hline Italy & 104 & 360 & $29 \%$ & $25.2(1.2)$ & $0(0 \%)$ & $(*)$ & 38 (37\%) & 41 (39\%) & 15 (14\%) & $6(6 \%)$ & $21(20 \%)$ \\
\hline Israel & 173 & 534 & $32 \%$ & $27.9(2.9)$ & $16(9 \%)$ & $11(6 \%)$ & $83(48 \%)$ & $40(23 \%)$ & $35(20 \%)$ & $5(3 \%)$ & $40(23 \%)$ \\
\hline Germany & 323 & 2000 & $16 \%$ & $23.8(3.9)$ & $6(2 \%)$ & $18(6 \%)$ & $98(31 \%)$ & $87(27 \%)$ & 69 (22\%) & $8(3 \%)$ & 77 (24\%) \\
\hline Switzerland & 60 & 221 & $27 \%$ & $25.8(2.2)$ & $4(7 \%)$ & $9(16 \%)$ & 22 (39\%) & 18 (31\%) & $8(14 \%)$ & $2(3 \%)$ & $10(17 \%)$ \\
\hline UK & 291 & 1810 & $16 \%$ & $24.7(4.6)$ & $22(8 \%)$ & 74 (27\%) & 99 (37\%) & $65(23 \%)$ & 53 (19\%) & $6(2 \%)$ & $59(21 \%)$ \\
\hline Canada & 127 & 592 & $21 \%$ & $24.6(4.1)$ & $2(2 \%)$ & $30(25 \%)$ & $26(21 \%)$ & $21(17 \%)$ & $21(17 \%)$ & $5(4 \%)$ & $26(21 \%)$ \\
\hline Brazil & 13 & 307 & $4 \%$ & $24.8(2.6)$ & $0(0 \%)$ & $2(17 \%)$ & $8(67 \%)$ & $9(75 \%)$ & $0(0 \%)$ & $1(8 \%)$ & $1(8 \%)$ \\
\hline Chile & 40 & 440 & $9 \%$ & $24.4(1.9)$ & $0(0 \%)$ & $0(0 \%)$ & $22(58 \%)$ & $14(36 \%)$ & $9(23 \%)$ & $3(8 \%)$ & $12(31 \%)$ \\
\hline $\begin{array}{l}\text { Hong } \\
\text { Kong }\end{array}$ & 45 & 250 & $18 \%$ & $23.7(2.1)$ & $1(2 \%)$ & $0(0 \%)$ & $24(53 \%)$ & $5(11 \%)$ & $8(18 \%)$ & $4(9 \%)$ & 12 (27\%) \\
\hline India & 66 & 263 & $25 \%$ & $22.2(1.1)$ & $8(13 \%)$ & 11 (17\%) & $24(38 \%)$ & 12 (19\%) & $5(8 \%)$ & $1(2 \%)$ & $6(9 \%)$ \\
\hline Iraq & 71 & 296 & $24 \%$ & $22.7(1.0)$ & $23(35 \%)$ & 20 (31\%) & 31 (48\%) & 13 (19\%) & $14(21 \%)$ & $8(12 \%)$ & 22 (33\%) \\
\hline Japan & 145 & 200 & $73 \%$ & $22.9(2.2)$ & $(*)$ & $(*)$ & 112 (79\%) & $37(29 \%)$ & $10(8 \%)$ & $1(1 \%)$ & $11(9 \%)$ \\
\hline Kenya & 182 & 254 & $72 \%$ & $24.8(1.8)$ & $28(18 \%)$ & $1(1 \%)$ & 75 (45\%) & $5(3 \%)$ & $7(4 \%)$ & $12(7 \%)$ & 19 (12\%) \\
\hline Nigeria & 95 & 104 & $91 \%$ & $24.3(2.1)$ & 8 (9\%) & $6(8 \%)$ & 48 (55\%) & $18(24 \%)$ & $3(4 \%)$ & $3(4 \%)$ & $6(8 \%)$ \\
\hline $\begin{array}{l}\text { South } \\
\text { Africa }\end{array}$ & 70 & 360 & $19 \%$ & $23.9(1.6)$ & $6(9 \%)$ & $38(55 \%)$ & $27(40 \%)$ & 19 (27\%) & $8(11 \%)$ & $1(1 \%)$ & $9(13 \%)$ \\
\hline Tanzania & $9+$ & $(*)$ & $(*)$ & $26.7(1.7)$ & $1(13 \%)$ & $1(11 \%)$ & $4(44 \%)$ & $2(33 \%)$ & $0(0 \%)$ & $0(\%)$ & $0(0 \%)$ \\
\hline Uganda & 56 & 74 & $76 \%$ & $24.3(1.5)$ & $2(4 \%)$ & $5(9 \%)$ & 34 (61\%) & 17 (34\%) & $0(0 \%)$ & $1(2 \%)$ & $1(2 \%)$ \\
\hline Combined & 2189 & 9135 & $24 \%$ & $24.6(3.1)$ & 141 (7\%) & $\begin{array}{l}237 \\
(14 \%)\end{array}$ & 869 (41\%) & $527(25 \%)$ & 307 (15\%) & $93(4 \%)$ & 400 (19\%) \\
\hline
\end{tabular}




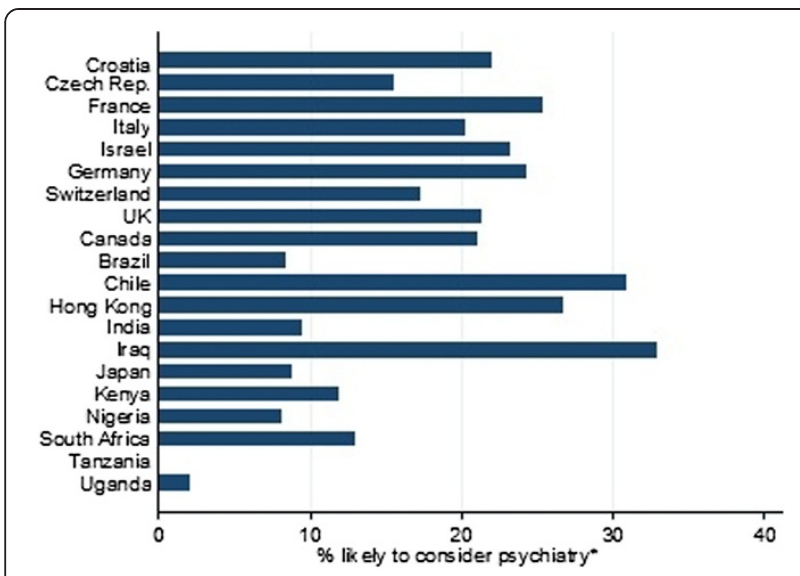

Figure 2 Variation in percentage of medical students seriously or definitely considering a career in psychiatry by country (alphabetical order). Key: *Combining 'definitely' and 'seriously considering' scores.

Preference of speciality when entering medical school was strongly associated with subsequent speciality choice. Perhaps unexpectedly, 78\% of those whose initial choice was psychiatry when entering medical school remained likely to consider specialisation in the subject by the end.

\section{Medical school factors associated with Choosing Psychiatry \\ Teaching methods, student ratings, and enrichment activities}

Table 2 illustrates the impact of teaching methods and activities on choice of a career in psychiatry.

Almost half (48\%) of those involved in a psychiatry club at university were likely to consider a career in the field, compared to only $18 \%$ who did not attend such a club. Students who had exposure to psychiatry lectures and tutorials were slightly less likely to consider a specialisation in psychiatry, whilst those with optional extras on the course were more likely to consider psychiatry as a career.

Interestingly, those who were taught psychology were less likely to consider specialising in psychiatry compared with other subjects.

\section{Clinical exposure factors}

The majority of clinical exposure factors were not associated with likelihood of choosing psychiatry (Table 3). However, those students exposed to acutely unwell patients were more likely to consider psychiatry as was the degree of clinical responsibility given to them especially risk assessment, or therapy. Nearly one third (31\%) of the group with most responsibility were likely to consider psychiatry compared to one fifth (around 20\%) for the remaining groups.

\section{Attitudes towards psychiatry}

Not surprisingly students with a positive attitude score were more likely to consider psychiatry, with $23 \%$ of this group considering it as a speciality, compared to only $12 \%$ of those with a negative attitude. Results of attitudes to psychiatry are shown in Table 5.

\section{Teaching exposure, attitudes \& career choice}

The association between ATP score and two other factors (quality of psychiatric placement, and number of exposures to psychiatric teaching) was examined using Spearman's rank correlation (Table 6). Quality of psychiatric placement was significantly associated with career choice and number of psychiatric teaching placements.

\section{Personality traits}

Interestingly there was no association between self-rated personality factors and likelihood of choosing psychiatry on the International English Mini-Markers scale (Table 7).

\section{Logistic regression}

Multilevel logistic regression was used to examine the joint effect of various factors upon likelihood of choosing a career in psychiatry. A backwards selection procedure was used to retain only the statistically significant variables. This final regression model is based on 1732 respondents. This gives the odds of being likely to choose a career in psychiatry in each category relative to the odds in a baseline category.

Six factors were found to be associated with students being likely to pursue a career in psychiatry (Table 8).

Those who gave more weight to their own vocation were three times more likely to choose psychiatry. Those who had a clear idea that they wanted to study psychiatry when entering medical school were 11 times more likely to consider specialising in psychiatry compared to

Table 5 Rating of psychiatry relative to other fields, ATP18 scores and relation to career choice

\begin{tabular}{|c|c|c|c|c|}
\hline Factor & Category & $\begin{array}{l}\text { Unlikely to } \\
\text { choose } \\
\text { psychiatry } \\
\text { n (\%) }\end{array}$ & $\begin{array}{l}\text { Likely to } \\
\text { choose } \\
\text { psychiatry } \\
\text { n (\%) }\end{array}$ & P-value \\
\hline \multirow{3}{*}{$\begin{array}{l}\text { Psychiatry relative } \\
\text { other specialities }^{(*)}\end{array}$} & Worse & $151(83 \%)$ & $32(17 \%)$ & \multirow[t]{3}{*}{0.30} \\
\hline & Similar & $414(77 \%)$ & $123(23 \%)$ & \\
\hline & Better & 232 (79\%) & $66(22 \%)$ & \\
\hline ATP score $(+)$ & - & $60.7(6.1)$ & $64.4(7.4)$ & $<0.001$ \\
\hline \multirow[t]{2}{*}{ ATP score } & $\begin{array}{l}\text { Negative } \\
\text { attitude }\end{array}$ & $415(88 \%)$ & $56(12 \%)$ & \multirow[t]{2}{*}{$<0.001$} \\
\hline & $\begin{array}{l}\text { Positive } \\
\text { attitude }(\neq)\end{array}$ & 429 (77\%) & $125(23 \%)$ & \\
\hline
\end{tabular}

(*) Combined variable based on 8 individual criteria, (†) Mean (standard deviation) reported, (¥) Positive attitude defined as score $>60$. 
Table 6 Quality \& quantity of teaching \& ATP-18 scores

\begin{tabular}{lll}
\hline Factor & $\begin{array}{l}\text { Correlation } \\
\text { coefficient }\end{array}$ & P-value \\
\hline Quality of psychiatric placement & 0.22 & $<0.001$ \\
$\begin{array}{l}\text { Number of exposures to psychiatric } \\
\text { teaching/placements }\end{array}$ & 0.21 & $<0.001$ \\
\hline
\end{tabular}

those who had no speciality choice on entering medical school.

Experience of a psychiatry special module made choice of psychiatry slightly more likely $(45 \%)$ than those who had no exposure. A university psychiatry club (with guest lectures and social events) and psychiatry elective (dedicated to either clinical work or study elsewhere) were strongly associated with career choice of psychiatry (3 times and 4 times more likely respectively).

The odds of choosing psychiatry dropped to almost half as large for those who had experienced didactic teaching. The results suggest that the odds of choosing psychiatry were $46 \%$ higher for participants with a positive attitude compared to those with a negative attitude towards psychiatry.

\section{Discussion}

This study set out to report on the career plans of final year medical students from 20 countries, with reference to factors identified from the literature as affecting psychiatry as a career choice.

\section{Strengths and limitations}

The main strengths of the study are the large multicountry sample size, with sufficient power to detect differences of the key variables. It is the first international study of its kind, and the first study to look at relative influences of multiple well described factors on psychiatric recruitment.

The main limitation is the relatively low response rates from some countries. This might be explained by a number of factors in those countries including selection bias which may reflect different attitudes towards psychiatry. Conversely, the higher than expected endorsement of a psychiatric career choice in some countries may represent

Table 7 Personality traits and likelihood of choosing psychiatry

\begin{tabular}{llll}
\hline $\begin{array}{l}\text { Personality trait } \\
\text { International English } \\
\text { Mini-Markers scale) }\end{array}$ & $\begin{array}{l}\text { Unlikely } \\
\text { mean (SD) }\end{array}$ & $\begin{array}{l}\text { Likely } \\
\text { mean (SD) }\end{array}$ & P-value \\
\hline Extraversion & $17.4(3.7)$ & $17.3(3.7)$ & 0.84 \\
Openness & $18.3(3.3)$ & $18.6(3.7)$ & 0.32 \\
Neuroticism & $16.0(3.7)$ & $15.7(4.0)$ & 0.55 \\
Conscientiousness & $17.5(4.2)$ & $17.4(4.3)$ & 0.72 \\
Agreeableness & $21.0(3.3)$ & $21.1(3.5)$ & 0.76 \\
\hline
\end{tabular}

Table 8 Logistical regression factors in choosing a psychiatric career

\begin{tabular}{|c|c|c|c|}
\hline Variable & Category & $\begin{array}{l}\text { Odds ratio } \\
(95 \% \mathrm{Cl})\end{array}$ & P-value \\
\hline \multirow{3}{*}{$\begin{array}{l}\text { Own vocation in } \\
\text { choosing medicine }\end{array}$} & Negative influence & 1 & \multirow[t]{3}{*}{$<0.001$} \\
\hline & No/slight influence & $1.49(0.85,2.61)$ & \\
\hline & Important influence & $3.01(1.61,5.91)$ & \\
\hline \multirow{3}{*}{$\begin{array}{l}\text { Speciality choice } \\
\text { on entering medical } \\
\text { school }\end{array}$} & No speciality & 1 & \multirow[t]{3}{*}{$<0.001$} \\
\hline & Psychiatry & $10.8(5.38,21.8)$ & \\
\hline & $\begin{array}{l}\text { Other } \\
\text { speciality }\end{array}$ & $1.13(0.81,1.59)$ & \\
\hline \multirow{2}{*}{$\begin{array}{l}\text { Psychiatry special } \\
\text { study module }\end{array}$} & No & 1 & \multirow[t]{2}{*}{0.03} \\
\hline & Yes & $1.45(1.05,2.01)$ & \\
\hline \multirow{2}{*}{$\begin{array}{l}\text { University psychiatry } \\
\text { club }\end{array}$} & No & 1 & \multirow[t]{2}{*}{$<0.001$} \\
\hline & Yes & $3.25(1.94,5.42)$ & \\
\hline \multirow[t]{2}{*}{ Psychiatry elective } & No & 1 & \multirow[t]{2}{*}{$<0.001$} \\
\hline & Yes & $4.28(2.87,6.38)$ & \\
\hline \multirow{2}{*}{$\begin{array}{l}\text { Psychiatry } \\
\text { lectures/ tutorials }\end{array}$} & No & 1 & \multirow[t]{2}{*}{$<0.001$} \\
\hline & Yes & $0.54(0.40,0.72)$ & \\
\hline
\end{tabular}

respondent selection bias. Different methods of administration of the questionnaire were unavoidable due to restricted Internet access in some countries, and lack of support for Japanese script on the online tools available. It is possible that this might have introduced bias, as reminders could be targeted at non-responders more easily using the online tools.

In the interests of developing a questionnaire sufficiently brief to improve response rates but remain useful, we decided $a$ priori against exploring a number of areas of interest. These included cultural, linguistic, religious and other social variables (for a review see Rao et al.[32]. The absence of qualitative data also limits the ability to address larger-scale issues such cultural and professional stigma towards mental health and psychiatry.

ATP-18 data was missing in three countries due to an undetected online survey system error. The cross sectional design was chosen as the most practicable to cover a wide range of countries, therefore direction of effect and causality cannot be demonstrated. The wide variation between countries may be obscured by pooling the data, although we attempted to address this in the statistical analysis. The lack of data from countries like the USA and regions like Australasia are a further limitation to generalisability especially to these areas. These countries were not included in the initial study because of logistical reasons. The intention was to remedy this in a second phase of the study pending further funding. Lastly, we did not correct for multiple testing because we were examining the effects of separate variables. Uncorrected, this approach may lead to Type 1 errors. 


\section{Interest in psychiatry}

Our finding that $4.5 \%$ of the sample was definitely interested in a career in psychiatry is consistent with previous estimates [33-36], and suggests that the sample was representative. Our survey was timed in the second half of the students' final year of medical school to capture their choices close to qualification. Previous research on decision stability [37-42] suggests that career decisions are becoming increasingly stable by this point. Between year 4 and qualification $56 \%$ will change their minds [38]. Of Goldacre and colleagues' cohort of psychiatrists, $64 \%$ who had made their decision in the first year post qualification remained within the field after 10 years [43].

Estimates of the percentage of students who consider psychiatry as a career option but have not made a definite decision vary by country and methodology, for example 9\% in the UK [44], 7.6\% in Pakistan [45] and 33\% in Israel [46]. Our combined finding was $15 \%$, with geographical variation ranging from $0-33 \%$, and thus broadly in line with previous results. The overall trend was for European countries and Canada to have higher rates for choosing psychiatry than African countries. Interestingly, Iraq has the highest rate at $33 \%$ which confirms previous reports that with the recognition of the psychiatric morbidity of war, post-conflict recruitment to psychiatry improves [47]. Funding and provision of mental health care in African countries with few psychiatrists, limited provision especially in rural areas and limited undergraduate teaching may affect recruitment although some attempts are being made to overcome these [48].

As mentioned above, funding, quality and availability of psychiatry training posts varies considerably worldwide, with only $68 \%$ of the world's countries offering psychiatry training $[7,8]$. Even if adequate numbers of people are interested in psychiatry, their decisions may be influenced by training job availability and prospects. For example, less than $1.8 \%$ of new training posts in the UK are for psychiatry and competition ratios are nearly 5 applicant for every 1 post [10]. While outside the scope of this paper, it would be reasonable for countries to ensure optimal training (and specialist) job availability to capture those newly graduating doctors interested in psychiatry.

\section{Pre-medical school factors}

The popularity of psychiatry in our study was greater for women, in line with trends seen in previous studies [49-51]. Flexible working patterns and role models may play a role in this decision. Our data did not confirm previous findings $\mathrm{s}$ that psychiatrists were more likely to come from urban areas [11].

There was a significant difference for strong internal vocation, and personal or family experience of physical or mental illness confirming previous findings [11,52,53].
There may also be an impact of societal stigma, as those choosing psychiatry placed less emphasis on the portrayal of doctors in the media on their choice of medicine as a career. Assessment of personal motivation for the career during interview and other selection procedures to medical school may select for students with these characteristics, so the importance of these factors for psychiatry recruitment should be recognised. [11,52,53].

Stigma, both cultural, personal and professional may negatively affect attitudes toward the mentally ill and psychiatry. This may in turn influence career choice before and during medical school; positive attitudes towards psychiatry increase the likelihood of choosing a career in the field [18]. However because undergraduate education appears to reduce stigma in several countries by improving attitudes teaching may indirectly improve psychiatry as a career prospect [54]. Furthermore, a recent meta-analysis showed that contact (with someone with mental illness, as may occur in clinical settings) was better than education at reducing stigma for adults [55].

More detail on the crucial area of stigma is beyond the scope of this paper. The interested reader is referred to a comprehensive review article on public and personal stigma [56] and professional stigma. We also recommend a recent meta-analysis on the public understanding of mental illness and stigma [57].

\section{Decision stability}

$2.7 \%$ our sample entered medical school with a desire to become a psychiatrist, and $78 \%$ of this group remained committed at year 5 . This group of early-deciders made up $12 \%$ of the total of those who were interested in psychiatry by the final year of medical school. Thirty percent of those choosing psychiatry in year 5 had entered medical school with any speciality choice, and 70\% did not have a preference. This is a lower figure than the $40 \%$ deciding before medical school found by Galeazzi [39] in a retrospective sample of psychiatry interns. The emphasis is different for the two groups: for early deciders it is ensuring a high conversion rate to psychiatry internship; and for those who develop their interest during medical school it is about standing out against other fields. Furthermore, reducing professional stigma (both from other doctors and mental health professionals themselves) during medical school may maintain this interest and reduce some of the attrition [18] This question warrants further exploration.

\section{Teaching exposure}

Our data on attitudes from the ATP-18 was in line with previous studies [58-64], showing the majority of students had positive attitudes towards psychiatry, which were positively correlated to the quality and quantity of teaching (Table 6). 
However, students' ratings of the quality of their teaching were not associated with career choice, except for the unexpected finding that exposure to didactic teaching (lectures) appears to decrease recruitment to psychiatry. This may reflect that fact that this was the commonest method of delivery of teaching, with 1334 of the sample endorsing it. Students who were exposed to problem based learning or e-learning were no more likely to choose psychiatry, but there was a trend $[\mathrm{p}=0.07]$ towards simulation teaching. It may also be that clinical exposure is rated more highly by students than didactic teaching as has been reported in several countries [65-67], or that clinical contact was better than education at reducing mental illness stigma [55]. It is also possible that the didactic training received by the students may be lacking in quality, depth, resources and other factors, perhaps painting an unflattering image of the field. Lastly, this counterintuitive finding may also represent Type 1 error. Because this result is not easily explained, and because teaching is a substantial part of the investment in the training of medical students, we recommend further studies on this subject.

\section{Enrichment activities}

Specific activities such as research and special study modules may be used by students to test out potential career choices. Electives and university psychiatry societies were important for recruitment to psychiatry in our sample, and it is possible that these may be further improved to enhance recruitment [26-28].

\section{Clinical factors}

Length and setting of clerkship made no difference to the likelihood of choosing psychiatry. Although previous work on clerkship setting has given conflicting results $[68,69]$, and in an international context there will be inherent variation in settings, length and quality of clinical attachment did not make a difference per se but the degree of responsibility did.

It is possible that the current generation of students have a greater awareness of the potential for recovery from severe mental illness, so the stimulating exposure to acute work is more influential. It is possible that those already interested may seek out greater clinical exposure.

The association between the level of responsibility given to students during their clerkship and choice of career [70] is confirmed in the present study. There are local projects such as a student psychotherapy scheme [71], where medical students offer psychodynamic therapy under close supervision from staff which has increased recruitment to psychiatry [43].

\section{Conclusions}

Overall, our findings are encouraging in that internationally there is a pool of $15 \%$ of students who would seriously consider psychiatry as a career. It is this group that is arguably the most critical to target at medical school in order to enhance recruitment. Our study has shown that there are specific aspects of undergraduate education that are associated with final year medical students choosing a career in psychiatry. Countries with lower rates of recruitment might look to their opposites to consider policy changes to improve local recruitment. Further studies are also needed in different countries to confirm prospectively specific national factors affecting recruitment to psychiatry.

\section{Competing interests}

The authors declare no competing financial or non financial interests. All authors have completed the Unified Competing Interest form at www. icmje.org/coi_disclosure.pdf (available on request from the corresponding author) and declare that (1) none have support from any company for the submitted work; (2) none have relationships with companies that might have an interest in the submitted work in the previous 3 years; (3) their spouses, partners, or children have no financial relationships that may be relevant to the submitted work; and (4) all have no non-financial interests that may be relevant to the submitted work.

\section{Authors' contributions}

The study was led by KF, GL, AM and DB. The article was drafted by GL and KF. All authors contributed to the submitted article. The guarantor is DB. Ethical approval, where required, was obtained in each country's relevant institution. In the UK ethical approval was granted by the ethics panels at each participating medical school. An independent statistician, PB, was employed in the study design and data analysis. All authors read and approved the final manuscript.

\section{Acknowledgements}

We thank all respondents for their time. We thank Mr Paul Bassett, who assisted in the study design and data analysis, and Elaine Gould, Quin Golding and Hannah Graham from the Royal College of Psychiatrists, UK, for their help in administration of the project.

\section{Funding}

The study was funded in part by a World Psychiatric Association (WPA) grant to the Royal College of Psychiatrists. The WPA had no influence on study design or in the collection, analysis, and interpretation of data; in the writing of the report; and in the decision to submit the article for publication. The researchers confirm their independence from the funders at the time of writing. All authors had full access to all of the data (including statistical reports and tables) in the study and can take responsibility for the integrity of the data and the accuracy of the data analysis.

The data has been presented to the WPA Board and recommendations made from the findings.

\section{ISOSCCIP Group (including Africa Mental Health Forum*)}

Dr. Yonas Baheretibeb Alemu, 13th Street, Lideta, P.O. Box 1176, Addis Ababa University, Ethiopia*.

Dr. Sammy Ohene, Head of the Department of Psychiatry, University of Ghana, P.O. Box 4236, Accra, Ghana*.

Dr. Muthoni Mathai, Lecturer, College Of Health Sciences University of Nairobi, P.O. BOX 30197, Nairobi, Kenya*.

Dr. Benson Gakinya, Consultant Psychiatrist and Head, Department of Mental Health, School of Medicine, Moi University, P.O. Box 3900-30100 Eldoret, Kenya, Kenya*.

Dr. Richard Uwakwa, Lecturer, Nnamdi Azikiwe University, P.O. Box 5025 Awka, Nigeria*

Dr. Femi Olugbile, Chief Medical Director, Lagos State University Teaching Hospital, 1-5 Oba Akinjobi Road, Ikeja IKEIA, Nigeria*.

Dr. Kiyeti Hauli, Weill Bugando University, College of Health Sciences, P.O. Box 1464 Mwanza, Tanzania*. 
Dr. Joyce Mugaza \& Prof. Gad Kilonzo Professor of Psychiatry, Muhimbili University of Health and Allied Sciences (MUHAS), P.O. Box 65001, Dar es salaam, Tanzania*

Prof. Seggane Musisi, Professor and Chair, Makerere Medical School, P.O. BOX 7062, Kampala, Uganda*.

Dr. Samuel Maling, Associate Dean, Mbarara University, P.O. Box 1410, Mbarara, Uganda*.

Dr. Paul Ravi, Head, Department of Psychiatry, University of Zambia, P.O. Box 32379, Lusaka, Zambia*.

Rubens Luis Folchini Fernandes (Fernandes, R.L.F.), Psychiatrist, Consultation Psychiatry Escola Paulista de Medicina, Universidade Federal de São Paulo, Brazil.

Luiz Antonio Nogueira-Martins (Nogueira Martins, L.A.), Psychiatrist, Escola Paulista de Medicina, Universidade Federal de São Paulo Consultation Psychiatry, Psychiatry Department, Borges Lagoa St., 5709 fl. - São Paulo, 04038-030, Brazil.

Jair de Jesus Mari (Mari, J.J.), Professor, Escola Paulista de Medicina, Universidade Federal de São Paulo, Rua Botucatu, 740, 4. andar, V. Clementino, São Paulo, 04023-062, Brazil.

Sergio Baldassin (Baldassin, S.) Psychiatrist, Faculdade de Medicina do ABC, Graduation Coordinator, Discipline of Psychiatry and Medical Psychology, Príncipe de Gales de Gales st., 821, Santo André, Sau Paulo, 09060-650, Brazil.

Nilson Rodrigues da Silva (Silva, N.R.), Psychologist, Faculdade de Medicina do $A B C$ " Príncipe de Gales de Gales st., 821, Santo André, Sau Paulo, 09060-650, Brazil.

Karen Saperson, Associate Chair, Education, Dept of Psychiatry \& Behavioural Neurosciences, McMaster University, 100-West $5^{\text {th }}$ St, Hamilton, ON, L9G1G3, Canada.

Martina Rojnic Kuzman, Consultant Psychiatrist, Zagreb University Hospital Centre, Kispaticeva 12, 10000 Zagreb, Croatia.

Petra Lovrec, Psychiatrist, Health Center Zagreb - West, Prilaz baruna Filipovica 11, 10000 Zagreb, Croatia.

Mia Smoljan, Psychiatrist, University Hospital Sisters of Charity, Vinogradska cesta 29, 10000 Zagreb, Croatia.

Benjamin Vicente, Professor, Facultad de Medicina, Universidad Católica de la Santísima Concepción, Chile.

Leonardo Rosel, Psychiatrist, Facultad de Medicina, Universidad Católica de la Santísima Concepción, Chile.

Alexander Nawka, Consultant Psychiatrist, Department of Psychiatry, First Faculty of Medicine, Charles University in Prague, KeKarlovu 11, Praha 2, 128 00, Czech Republic.

Lucie Nawkova, Consultant Psychiatrist, Department of Psychiatry, First Faculty of Medicine, Charles University in Prague, KeKarlovu 11, Praha 2, 128 00, Czech Republic.

Boris Dvoracek, Consultant Psychiatrist, Department of Psychiatry, First Faculty of Medicine, Charles University in Prague, KeKarlovu 11, Praha 2, 128 00, Czech Republic.

Olivier Andlauer, Consultant Psychiatrist, CHU Besancon, 3 Bd Fleming, 25000 Besancon, France.

Emmanuel Haffen, Co-Director EA 481 Laboratoires de Neurosciences, Université de Franche-Comté, 1 place du maréchal Leclerc, 25000 Besançon, France.

Daniel Sechter, Head of the Department of Psychiatry, CHU Besancon, $3 \mathrm{Bd}$ Fleming, 25000 Besancon, France.

Dr William Guicherd, Consultant Psychiatrist, C.H. la Chartreuse, 21000, Dijon, France. Bernard Bonin, Head of the Department of Psychiatry, CHU de Dijon, 21000 Dijon, France.

Iris Tatjana Calliess, Consultant Psychiatrist, Volkhard Fischer, Consultant Psychiatrist, Anke Mittelstädt, Consultant Psychiatrist, Department of Psychiatry, Social Psychiatry and Psychotherapy, Hannover Medical School, Carl Neuberg Str. 1, 30625, Hannover, Niedersachsen, Germany. Vanessa Wong, Resident Psychiatrist, Hong Kong University, Hong Kong. PSVN Sharma, Professor \& HOD, Sumit Deora, Psychiatrist, \& Suma Udupa, Psychiatrist, Department of Psychiatry, Kasturba Medical College, Manipal University, Manipal - 576104, Karnataka, India.

A-Rasoul Yasiri, Chairman of the Scientific Council of Psychiatry, Iraqi Board for Medical Specializations, PO Box 61029, Medical Assembly, Bab Al-Moadam, Baghdad, Iraq.

Basil Al-Chalabi, Psychiatrist, Mosul School of Medicine, Mosul, Iraq. Ali Al-Hamzawi, Professor of Psychiatry, Quadissiya School of Medicine, Iraq. Sirwan Ali, Psychiatrist, Erbil School of Medicine, Erbil, Iraq.
Akeel Al-Sabbagh, Psychiatrist, Basrah School of Medicine, Basrah, Iraq Eyal Dahan \& Karin Schlossberg, Consultant Psychiatrists, Lev Hasharon Mental Health Medical Center, Pardesiya, Israel.

Silvia Ferrari, Consultant Psychiatrist, Department of Diagnostic-Clinical Medicine and Public Health, Policlinico di Modena, Via del Pozzo 71, 41124 Modena, Italy.

Corinna Reggianini, Trainee in Psychiatry, Department of Diagnostic-Clinical Medicine and Public Health, Policlinico di Modena, Via del Pozzo 71, 41124 Modena, Italy.

Giorgio Mattei, Trainee in Psychiatry, Department of Diagnostic-Clinical

Medicine and Public Health, Policlinico di Modena, Via del Pozzo 71, 41124 Modena, Italy.

Luca Pingani, PhD Student, Department of Diagnostic-Clinical Medicine and Public Health, Policlinico di Modena, Via del Pozzo 71, 41124 Modena, Italy. Takahiro A. Kato, Associate Professor \& Shigenobu Kanba, Professor, Graduate School of Medical Sciences, Kyushu University, Innovation Center for Medical Redox Navigation, Kyushu University, Address: 3-1-1 Maidashi Higashi-ku, Fukuoka 812-8582, Japan.

Masaru Tateno, Professor, Division of Neuropsychiatry, Sapporo Medical University, South 1, West16, Chuo-ku, Sapporo, Hokkaido, 060-8543, Japan. Soraya Seedat, Professor of Psychiatry, Department of Psychiatry,

Stellenbosch University, Faculty of Medicine and Health Sciences "PO Box 19063, Tygerberg, 7505, Cape Town, South Africa.

Sharain Suliman, Researcher, Department of Psychiatry, Stellenbosch University, Faculty of Medicine and Health Sciences „PO Box 19063, Tygerberg, 7505, Cape Town, South Africa.

Wolfgang Gerke, Teaching Coordinator, University Hospital Zurich, Klinik für Alterspsychiatrie, Gerontopsychiatrisches Zentrum Hegibach, CH 8032 Zurich, Switzerland.

Ulrich Schnyder, Professor, Department of Psychiatry and Psychotherapy, University Hospital Zurich, Culmannstrasse 8, CH 8091 Zurich, Switzerland. François Ferrero, Professor, University of Geneva, Department of Psychiatry, Ch. du Petit-Bel-Air 2, CH 1225Chêne-Bourg, Geneva, Switzerland.

Guido Bondolfi, Associate Professor, University of Geneva, Department of Psychiatry, Ch. du Petit-Bel-Air 2, CH 1225Chêne-Bourg.

Neel Halder, Consultant Psychiatrist, Alpha Hospital Bury \& Senior Honorary Lecturer, University of Manchester, Buller Street, Bury, BL8 2BS.

Christiana Hadjidemetriou, Foundation Year 2 Doctor, Old Age Psychiatry, Lancashire Care, Royal Blackburn Hospital, Haslingden Road, East Lancashire, BB2 $3 \mathrm{HH}$.

Rachel Pearson, General Practice Specialist Trainee, North Manchester General Hospital, Delaunays Road, Crumpsall, Manchester. M8 5RB.

\section{Author details}

${ }^{1}$ Oxleas NHS Foundation Trust, 68 The Heights, Charlton, London SE7 8JH, UK. ${ }^{2}$ Castel Hospital, Guernsey GY5 7NJ, UK. ${ }^{3}$ Surrey and Borders NHS Trust, 18 Mole Business Park, Leatherhead, Surrey KT22 7AD, UK. ${ }^{4}$ Africa Mental Health Foundation, 1st Floor Gakuo Court, Lower Hill Road, Off Haile Sellasie Avenue, P.O Box 48423, 00100 Nairobi, Kenya. ${ }^{5}$ Mental Health and Cultural Diversity, PO25, Health Service and Population Research Department, Institute of Psychiatry, King's College London, David Goldberg Centre, De Crespigny Park, London SE5 8AF, UK.

Received: 29 May 2013 Accepted: 18 December 2013

\section{Published: 15 January 2014}

\section{References}

1. The Lancet Psychiatry's identity crisis. The Lancet 2012, 379(9823):1274.

2. Cooper B: British psychiatry and its discontents. JRSM 2010, 103(10):397-402.

3. Katschnig $\mathrm{H}$ : Are psychiatrists an endangered species? Observations on internal and external challenges to the profession. World Psychiatry 2010 $9(1): 21-28$.

4. Oyebode F, Humphreys M: The future of psychiatry. Br J Psychiatry 2011, 199(6):439-440.

5. WHO: mhGAP: Mental Health Gap Action Programme: scaling up care for mental, neurological and substance use disorders [pdf report]; 2008. [cited 2009 6/6/09]; Available from: http://www.who.int/mental_health/ mhgap_final_english.pdf.

6. Maj M: The WPA Action Plan 2008-2011; 2008. [cited 2009 11/06/2009]; Available from: http://www.ncbi.nlm.nih.gov/pmc/articles/PMC2559914/. 
7. Rojnic Kuzman M, Giacco D, Simmons M, Wuyts P, Bausch-Becker N, Favre G, Nawka A: Are there differences between training curricula on paper and in practice? Views of European trainees. World Psychiatry 2012, 11(2):135

8. WHO: Atlas: psychiatric education and training across the world 2005. Geneva: WHO; 2005

9. Rao NR: Recent trends in psychiatry residency workforce with special reference to international medical graduates. Acad Psychiatry 2003, 27(4):269-276.

10. RCPsych: Fill rate and competition ratios for CT1 August 2012 intake; 2012. [cited 2013 13.5.13]; Available from: http://www.rcpsych.ac.uk traininpsychiatry/nationalrecruitment/fillratesandcompetition.aspx.

11. Eagle PF, Marcos LR: Factors in medical students' choice of psychiatry. Am J Psychiatry 1980, 137(4):5.

12. Sierles FS, Dinwiddle S, Patro D, Atre-Vaidya N, Schrift MJ, Woddard J: Factors affecting medical student choice of psychiatry. Academic Psychiatry 2003, 27:260-26.

13. Brockington I, Mumford D: Recruitment into psychiatry. Br J Psychiatry 2002, 180:307-312

14. Thompson DJ, Sims ACP: Malaise in psychiatric recruitment and its remedy. Psychiatric Bulletin 1999, 23:227-229.

15. Brown N, Vassilas CA, Oakley C: Recruiting psychiatrists - A Sisyphean task? Psychiatric Bulletin 2009, 31(11):300-392.

16. Sierles FS, Yager J, Weissman SH: Recruitment of U.S. medical graduates into psychiatry: reasons for optimism, sources of concern. Acad Psychiatry 2003, 27(4):252-259.

17. Tamaskar P, McGinnis RA: Declining interest in psychiatry. Jama 2002, 287:1.

18. El-Sayeh H, Budd S, Waller R, Holmes J: How to win the hearts and minds of students in psychiatry. Advances in Psychiatric Treatment 2006, 12:182-192.

19. Feldmann TB: Medical students' attitudes toward psychiatry and mental disorders. Acad Psychiatry 2005, 29(4):354-356.

20. Buckley PF, Madaan V: Leadership and professional workforce development. Psychiatr Clin North Am 2008, 31(1):105-122.

21. Stoudemire A: Quo vadis, psychiatry? Problems and potential for the future of medical student education in psychiatry. Psychosomatics 2000, 41(3):204-209

22. Newton DA, Grayson MS, Newton DA, Grayson MS: Trends in career choice by US medical school graduates. Jama 2003, 290(9):1179-1182.

23. Lunn B: Recruitment into psychiatry: an international challenge. Aust $N Z$ J Psychiatry 2011, 45(805):807.

24. Eagles JM, Wilson S, Murdoch JM, Brown T: What impact do undergraduate experiences have upon recruitment into psychiatry? Psychiatric Bulletin 2007, 31(2):70-72.

25. Farooq K, Lydall GJ, Bhugra D: Research into recruitment: critical gaps in the literature. Int Rev Psychiatr 2013, 25(4):366-370

26. Lofchy J, Brunet A, Silver I: The psychiatry institute for medical students: a novel recruitment strategy. Acad Psychiatry 1999, 23:6.

27. Mihalynuk T, Leung G, Fraser J, Bates J, Snadden D: Free choice and career choice: Clerkship electives in medical education. Med Educ 2006, 40(11):1065-1071.

28. Weintraub W, Plaut SM, Weintraub E: Recruitment into psychiatry: increasing the pool of applicants. Can J Psychiatry 1999 44(5):473-477.

29. Wilkinson G: Medical students' attitudes to psychiatry at the end of the clinical curriculum. Psychol Med 1983, 13(4):665-668.

30. Thompson ER: Development and validation of an international English big-five mini-markers. Pers Indiv Differ 2008, 45(6):542-548.

31. Feifel D, Moutier CY, Swerdlow NR: Attitudes toward psychiatry as a prospective career among students entering medical school. Am J Psychiatr 1999, 156(9):1397-1402.

32. Rao NR, Meinzer AE, Manley M, Chagwedera I: International medical students' career choice, attitudes toward psychiatry, and emigration to the United States: examples from India and Zimbabwe. Acad Psychiatry 1998, 22:117-126.

33. Lambert TW, Goldacre MJ, Turner G: Career choices of United Kingdom medical graduates of 1999 and 2000: questionnaire surveys. Br Med J 2003, 326:194-195.

34. Balon R, Franchini GR, Freeman PS, Hassenfeld IN, Keshavan MS, Yoder E: Medical students' attitudes and views of psychiatry: 15 years later. Acad Psychiatry 1999, 23:30-36.
35. Pailhez G, Bulbena A, Coll J, Ros S, Balon R: Attitudes and views on psychiatry: a comparison between Spanish and U.S. medical students. Acad Psychiatry 2005, 29(1):82-91

36. Bulbena A, Pailhez G, Coll J, Balon R: Changes in the attitudes towards psychiatry among Spanish medical students during training in psychiatry. Eur J Psychiatr 2005, 19:79-87.

37. Compton MT, Frank E, Elon L, Carrera J: Changes in U.S. medical students' specialty interests over the course of medical school. J Gen Intern Med 2008, 23(7):1095-1100.

38. Mahoney R, Katona C, McParland M, Noble L, Livingston G: Shortage specialties: changes in career intentions from medical student to newly qualified doctor. Med Teach 2004, 26(7):650-654.

39. Galeazzi GM, Secchi C, Curci P: Current factors affecting the choice of psychiatry as a speciality: an Italian study. Acad Psychiatry 2003, 27:74-81.

40. Lambert TW, Turner G, Fazel S, Goldacre MJ: Reasons why some UK medical graduates who initially choose psychiatry do not pursue it as a long-term career. Psychol Med 2006, 36(5):679-684

41. Goldacre MJ, Lambert TW: Stability and change in career choices of junior doctors. Med Educ 2002, 34:700-707.

42. Goldacre MJ, Davidson JM, Lambert TW: Career choices at the end of the pre-registration year for doctors who qualified in the United Kingdom in 1996. Med Educ 1999, 33:882-889.

43. Goldacre MJ, Turner G, Fazel S, Lambert T: Career choices for psychiatry: national surveys of graduates of 1974-2000 from UK medical schools. [erratum appears in Br J Psychiatry. 2005 Apr;186:357]. Br J Psychiatry 2005 186:158-164.

44. Lambert TW, Davidson JM, Evans J, Goldacre MJ: Doctors' reasons for rejecting initial choices of specialties as long-term careers. Med Educ 2003, 37:312-318.

45. Syed EU, Siddiqi MN, Dogar I, Hamrani MM, Yousafzai AW, Zuberi S: Attitudes of pakistani medical students towards psychiatry as a prospective career: a survey. Acad Psychiatry 2008, 32(2):160-164

46. Abramowitz MZ, Bentov-Gofrit D, Abramowitz MZ, Bentov-Gofrit D: The attitudes of Israeli medical students toward residency in psychiatry. Acad Psychiatry 2005, 29(1):92-95.

47. Sierles FS, Taylor MA: Decline of U.S. medical student career choice of psychiatry and what to do about it. Am J Psychiatry 1995, 152(10):1416-1426.

48. Ndetei DM, Ongecha-Owuor F, Mutiso V, Kuria M, Khasakhala L, Kokonya D: The challendes of human resources in mental health in Kenya. South African Psychiatry Review 2007, 10:433-436.

49. Gjerberg E: Gender diffferences in doctors' preference - and gender difference in final specialisation. Soc Sci Med 2002, 54:591-605.

50. Gjerberg E: Medical women - towards full integration? An analysis of the speciality choices made by two cohorts of Norwegian doctors. Soc Sci Med 2001, 52:331-343.

51. Lambert EM, Holmboe ES: The relationship between speciality choice and gender of U.S. medical students, 1990-2003. Acad Med 2005, 80:797-802

52. Frank $E$, Boswell $L$, Dickstein $L$ : Characteristics of female psychiatrists. Am J Psychiatry 2001, 158:205-212.

53. Rajagopal S, Rehill KS, Godfrey E: Psychiatry as a career choice compared with other specialties: a survey of medical students. Psychiatr Bull 2004 28:444-446

54. Altindag A, Yanik M, Ucok A, Alptekin K, Ozkan M: Effects of an antistigma program on medical students' attitudes towards people with schizophrenia. Psychiatry Clin Neurosci 2006, 60(3):283-288.

55. Corrigan PW, Morris SB, Michaels PJ, Rafacz JD, Rusch N: Challenging the public stigma of mental illness: a meta-analysis of outcome studies. Psychiatric Services 2012, 63(10):963-973.

56. Corrigan PW, Watson AC: Understanding the impact of stigma on people with mental illness. World Psychiatr 2002, 1(1):16-20.

57. Schomerus G, Schwahn C, Holzinger A, Corrigan PW, Grabe HJ, Carta MG Angermeyer MC: Evolution of public attitudes about mental illness: a systematic review and meta-analysis. Acta psychiatrica Scandinavica 2012, 125(6):440-452.

58. Maidment R, Livingston G, Katona M, Whitaker E, Katona C: Carry on shrinking: career intentions and attitudes to psychiatry of prospective medical students. Psychiatric Bulletin 2003, 27:30-32.

59. Maidment R, Livingston G, Katona C, McParland M, Noble L: Change in attitudes to psychiatry and intention to pursue psychiatry as a career in newly qualified doctors: a follow-up of two cohorts of medical students. Med Teach 2004, 26(6):565-569.

60. Ndetei DM, Khasakhala L, Ongecha-Owuor F, Kuria M, Mutiso V, Syanda J, Kokonya D: Attitudes toward psychiatry: a survey of medical students at the University of Nairobi, Kenya. Acad Psychiatry 2008, 32(2):154-159. 
61. Al-Ansari A, Alsadadi A: Attitude of Arabian Gulf University medical students towards psychiatry. Educ Health 2002, 15:180-188.

62. Kuhnigk O, Strebel B, Schilauske J, Jueptner M: Attitudes of medical students towards psychiatry: effects of training, courses in psychiatry, psychiatric experience and gender. Adv Health Sci Educ Theory Pract 2007, 12(1):87-101.

63. Strebel B, Obladen M, Lehmann E, Gaebel W: Attitude of medical students to psychiatry. A study with the German translated, expanded version of the ATP-30].[erratum appears in Nervenarzt 2000 Jul;71(7):579. Nervenarzt 2000, 71(3):205-212.

64. Tharyan P, John T, Tharyan A, Braganza D: Attitudes of 'tomorrow's doctors' towards psychiatry and mental illness. Natl Med J India 2001, 14:355-359.

65. Niedermier JA, Bornstein R, Brandemihl A: The junior medical student psychiatry clerkship: curriculum, attitudes, and test performance. Acad Psychiatry 2006, 30(2):136-143.

66. Lampe L, Coulston C, Walter G, Malhi G: Up close and personal: medical students prefer face-to-face teaching in psychiatry. Australas Psychiatry 2010, 18(4):354-360.

67. Lampe L, Coulston C, Walter G, Malhi G: Familiarity breeds respect: attitudes of medical students towards psychiatry following a clinical attachment. Australas Psychiatry 2010, 18(4):348-353.

68. Bobo WV, Nevin R, Greene E, Lacy TJ: The effect of psychiatric third-year rotation setting on academic performance, student attitudes, and specialty choice. Acad Psychiatry 2009, 33(2):105-111.

69. Clardy JA, Thrush CR, Guttenberger VT, Goodrich ML, Burton RPD: The junior psychiatric clerkship and medical students' interest in psychiatry. Acad Psychiatry 2000, 24:6.

70. Kasuboski D, Marshall J: Responsibility and relevance in a psychiatric clerkship. J Med Educ 1973, 48(8):752-757.

71. Yakeley J, Shoenberg P, Heady A: Who wants to do psychiatry? The influence of a students psychotherapy scheme - a 10-year retrospective study. The Psychiatrist 2004, 28:208-212.

doi:10.1186/1472-6920-14-12

Cite this article as: Farooq et al:: Why medical students choose psychiatry - a 20 country cross-sectional survey. BMC Medical Education 2014 14:12.

\section{Submit your next manuscript to BioMed Central and take full advantage of:}

- Convenient online submission

- Thorough peer review

- No space constraints or color figure charges

- Immediate publication on acceptance

- Inclusion in PubMed, CAS, Scopus and Google Scholar

- Research which is freely available for redistribution 